\title{
Viral pro-survival proteins block separate stages in Bax activation but changes in mitochondrial ultrastructure still occur
}

\author{
JR Cross ${ }^{1}$, A Postigo ${ }^{1}, K_{\text {Blight }}{ }^{1}$ and J Downward ${ }^{\star, 1}$
}

\begin{abstract}
Mitochondrial dysfunction mediated by Bax and Bak is a critical step in mammalian cell apoptosis. However, the molecular mechanism of Bax activation remains unknown and has been difficult to investigate due to its rapid and stochastic nature. It is currently unclear whether mitochondria play a passive role in the initiation of apoptosis, remaining unaffected by cell stresses until Bax and Bak are active, or whether they actively participate in Bax/Bak activation. Here, two viral proteins, E1B19K and BHRF1, are examined for their ability to block Bax activation at different steps and thereby reveal the timing of mitochondrial changes during apoptosis. We demonstrate that BHRF1 strongly inhibits Bax activation but not upstream apoptotic signaling events, while E1B19K permits initial stages of Bax activation but prevents the subsequent oligomerization of Bax that is required for mitochondrial dysfunction. In this defined system we show that changes in mitochondrial ultrastructure, characteristic of cells undergoing apoptosis, precede Bax activation and are not blocked by E1B19K and BHRF1. We suggest that the ability of mitochondria to respond to apoptotic stress prior to Bax activation indicates that these organelles may play a direct role in activating Bax.
\end{abstract}

Cell Death and Differentiation (2008) 15, 997-1008; do:10.1038/cdd.2008.14; published online 15 February 2008

Apoptosis is required for correct development and organismal homeostasis, while defects in apoptosis contribute to the progression of cancer and degenerative diseases. The onset of mitochondrial dysfunction, characterized by the loss of mitochondrial membrane potential $\left(\Delta \psi_{\mathrm{m}}\right)$ and the release of mitochondrially sequestered proteins, such as cytochrome $c$ (Cyt-c), has been shown to be a critical control point in the apoptotic program and is followed by activation of cytosolic effector caspases leading to cell death. ${ }^{1}$

$\mathrm{Bcl}-2$ family proteins have emerged as important regulators of apoptosis since they govern mitochondrial integrity. The pro-apoptotic Bcl-2 family members Bax and Bak are absolutely required for mitochondrial dysfunction during apoptosis and cells isolated from mice deficient in both Bax and Bak are protected from apoptosis, failing to release Cyt- $c$ in response to diverse apoptotic stimuli. In healthy cells, Bax is a predominantly cytoplasmic protein, while Bak is constitutively localized to mitochondria. During apoptosis both proteins undergo conformational change, including at their $\mathrm{N}$ termini, ${ }^{2,3}$ to become active and enter into mitochondrially associated foci. ${ }^{4}$ This correlates with the onset of mitochondrial dysfunction, loss of $\Delta \psi_{\mathrm{m}}$ and release of Cyt- $c$.

Pro-survival members of the Bcl-2 family, such as $\mathrm{Bcl}-2$ and $\mathrm{Bcl}-\mathrm{XL}$, act to oppose Bax and Bak activation whereas a further group of pro-apoptotic Bcl-2 proteins, the BH3-only proteins, are activated by diverse cellular stresses and can bind and inactivate the $\mathrm{Bcl}-2$ pro-survival proteins. ${ }^{5} \mathrm{BH} 3-$ only proteins, most notably tBid, can also interact with Bax and Bak and result in their direct activation, ${ }^{6}$ although this interaction has been difficult to detect in vivo. ${ }^{7}$ In addition to their role in binding BH3-only proteins, Bcl-2 pro-survival proteins can function to directly bind and hold Bak inactive. ${ }^{8}$ However, a large fraction of the cellular pool of Bax is cytoplasmic and monomeric, ${ }^{9}$ and so a directly analogous mechanism by which Bax is held in check by the predominantly membranebound Bcl-2 pro-survival proteins seems unlikely. Therefore both the mechanism by which Bax is initially activated in cells undergoing apoptosis and the connection between inhibition of the pro-survival Bcl-2 proteins by $\mathrm{BH} 3-o n l y$ proteins and the promotion of Bax activation, still remain unclear.

Many viruses have developed strategies to modulate the apoptotic signaling pathways of infected host cells to promote productive infection. ${ }^{10}$ Some viral pro-survival proteins, such as Epstein-Barr virus BHRF1 and human herpes virus 8 vBCL-2, share structural and sequence homology with cellular Bcl-2 proteins. ${ }^{11}$ Others, such as adenovirus E1B19K, vaccinia virus F1L, human cytomegalovirus vMIA and myxoma virus $\mathrm{M} 11 \mathrm{~L}$, share very low or no sequence homology with $\mathrm{Bcl}-2$ proteins, but are nevertheless able to directly target and inhibit Bax and Bak oligomerization. ${ }^{12-17}$ $\mathrm{M} 11 \mathrm{~L}$ has structural homology to $\mathrm{Bcl}-2$ proteins despite a lack of sequence homology ${ }^{18}$ but structures are not yet available for other viral inhibitors of Bax/Bak. E1B19K is particularly interesting since it blocks apoptosis in infected cells by binding Bax and Bak, preventing their oligomerization and association. $^{12,19-21}$

\footnotetext{
${ }^{1}$ Cancer Research UK London Research Institute, 44 Lincoln's Inn Fields, London WC2A 3PX, UK

${ }^{*}$ Corresponding author: J Downward, Signal Transduction Laboratory, Cancer Research UK London Research Institute, 44 Lincoln's Inn Fields, London, WC2A 3PX, UK. Tel: + 0207269 3533; Fax: + 0207269 3094; E-mail: downward@ cancer.org.uk

Keywords: Bax; Bak; BHRF1; E1B19K; mitochondrial ultrastructure

Abbreviations: $\Delta \psi_{\mathrm{m}}$, mitochondrial membrane potential; Cyt- $c$, cytochrome $c$; TMRE, tetramethylrhodamine ethyl ester; tBid, truncated Bid

Received 02.5.07; revised 04.1.08; accepted 07.1.08; Edited by JM Hardwick; published online 15.2.08
} 
Physical changes in mitochondrial ultrastructure have been seen in both purified mitochondria and intact cells undergoing changes in metabolism. ${ }^{22-24}$ Similar changes have been observed during apoptosis, ${ }^{25-27}$ however, these changes have yet to be correlated with Bax activation status. It is therefore unclear whether changes in mitochondrial structure during apoptosis are a secondary response to Bax and Bak activation, occurring only in cells committed to die, or can occur prior to Bax/Bak activation.

We initially used live cell video microscopy to reveal there is heterogeneity in the timing of Bax activation both at the single cell and population level. This rapid and asynchronous nature of Bax activation confounds a detailed characterization of exactly when mitochondrial ultrastructural changes first occur. We reasoned that viral proteins that can inhibit Bax/Bak activation would provide a strategy to block mitochondrial dysfunction and thereby observe when mitochondria respond to pro-apoptotic signals. Such an approach eliminates the need to rely on cells that may have adapted to the genetic absence of Bax and Bak, or the consequent predominance of pro-survival $\mathrm{Bcl}-2$ proteins. We show that mitochondrial remodeling and matrix condensation occurs in response to the apoptotic stimulus independently of Bax and Bak activation. We suggest that if mitochondria can respond to the stress of an apoptotic insult even when Bax and Bak are blocked by viral proteins, then such changes could contribute to Bax/Bak activation in the absence of viral proteins.

\section{Results}

During apoptosis Bax and Bak undergo a dramatic conformational change and enter into mitochondrially associated foci. Bax tagged at the N-terminus with GFP can be used to visualize this process in live cells. U2OS human osteosarcoma cells or MCF10A human untransformed immortalized breast epithelial cells were transfected with GFP-Bax and $24 \mathrm{~h}$ later cells were loaded with TMRE to visualize the location of energized mitochondria. Cells were then treated with UV irradiation or with an activating antibody against the Fas death receptor together with cycloheximide (FasL/CHX), to induce apoptosis. In all conditions tested, GFP-Bax activation occurred stochastically throughout the cell population and was characterized by the sudden and rapid redistribution of GFP-Bax into mitochondrially associated foci and coincident mitochondrial dysfunction, as measured by a loss of $\Delta \psi_{\mathrm{m}}$ (Figure 1a). Complete loss of $\Delta \psi_{\mathrm{m}}$ occurred within an $\sim 5$-min period although this was composed of the very rapid ( $<1 \mathrm{~min}$ ) loss of $\Delta \psi_{\mathrm{m}}$ at individual mitochondria combined with a degree of heterogeneity in the timing at which loss of $\Delta \psi_{\mathrm{m}}$ occurred at different mitochondria in the same cell (Figure 1a, Videos 1-3). In some cases GFP-Bax activation in one part of the cell could precede the activation in a neighboring subcellular region. An extreme example is shown in Figure 1b, Video 4 where GFP-Bax first becomes active in a peripheral region, separated from the main cell body by a narrow cytoplasmic projection (Figure 1b, 381/431 min). This cell underwent morphological changes such that the region containing active Bax retracted inwards towards the main cell body, leading to rapid activation of GFP-Bax and loss of $\Delta \psi_{\mathrm{m}}$ throughout the rest of the cell (Figure 1b, 528/529 min). These observations demonstrate that Bax activation is a rapid and coordinated event at the single cell level but there can be some heterogeneity in exact timing of individual mitochondria losing $\Delta \psi_{\mathrm{m}}$.

We next wanted to investigate the effect of Bax activation on mitochondrial ultrastructure and in particular to address whether mitochondria respond to an apoptotic stimulus prior to Bax activation. Such analysis is complicated by the rapid and asynchronous nature of apoptotic cell deaths. At the level of a cell population most cells have either yet to initiate Bax activation or have progressed rapidly through to become late stage apoptotic bodies. In addition, identifying cells in the earliest stages of Bax activation in samples imaged by electron microscopy for ultrastructural analysis remains technically challenging.

We therefore sought to determine whether viral proteins that protect cells against apoptosis could be used to further dissect the relationship between Bax activation and mitochondrial dysfunction. We selected two viral proteins: BHRF1 from Epstein-Barr virus is a Bcl-2 sequence homolog and E1B19K from adenovirus, which has very limited sequence homology to the cellular $\mathrm{Bcl}-2$ proteins but still protects against apoptosis. ${ }^{11}$ E1B19K and BHRF1 were stably expressed in MCF10A cells by retroviral transduction and control cell lines were generated over-expressing the cellular pro-survival proteins $\mathrm{Bcl}-2$ and $\mathrm{Bcl}-\mathrm{XL}$, or infected with empty retrovirus (Figure 2a). Cells were treated with FasL/CHX, a physiologically relevant stimulus since virally infected cells are targeted by the immune system through activation of TNF family receptors including Fas. Apoptosis was quantified by measuring the proportion of cells with fragmented (sub-G1) DNA content (Figure 2b). Overexpression of Bcl-2 and Bcl-XL provided moderate protection to the cells relative to empty vector control cells, however, expression of either E1B19K or BHRF1 was strongly protective and the majority of cells were still alive after more than $14 \mathrm{~h}$ (Figure $2 \mathrm{~b}$ ). Western blot analysis of whole cell lysates revealed that events downstream of death receptor activation, but upstream of the mitochondria - the processing of pro-caspase-8, the cleavage of full length Bid and the caspase- 8 dependent cleavage of the pro-form of casapse- 3 - all proceeded at the same rate in all cells, independently of the presence of prosurvival proteins (Figure 2c; pre-mitochondrial). However, events downstream of mitochondria - the processing of procaspase-9 and the cleavage of DNA repair enzyme poly (ADP-ribose) polymerase-1 (PARP), a classical marker for apoptosis - occurred only in cell lines where significant death was also observed and was almost completely blocked by expression of E1B19K and BHRF1 (Figure 2c; postmitochondrial). The caspase-8-dependent cleavage of procaspase-3 was evident in all cells; however, this was not always sufficient to generate effector caspase activity and further caspase-9-dependent processing from p20 to p17 was required for full activation (Figure $2 \mathrm{c}$ ), a similar observation has been made in other systems. ${ }^{19}$ Together, these results demonstrate that while overexpression of $\mathrm{Bcl}-2$ and $\mathrm{Bcl}-\mathrm{XL}$ offers MCF10A cells modest protection against FasL/CHXinduced apoptosis, the viral proteins E1B19K and BHRF1 offered much greater protection and are acting at the level of the mitochondria. 

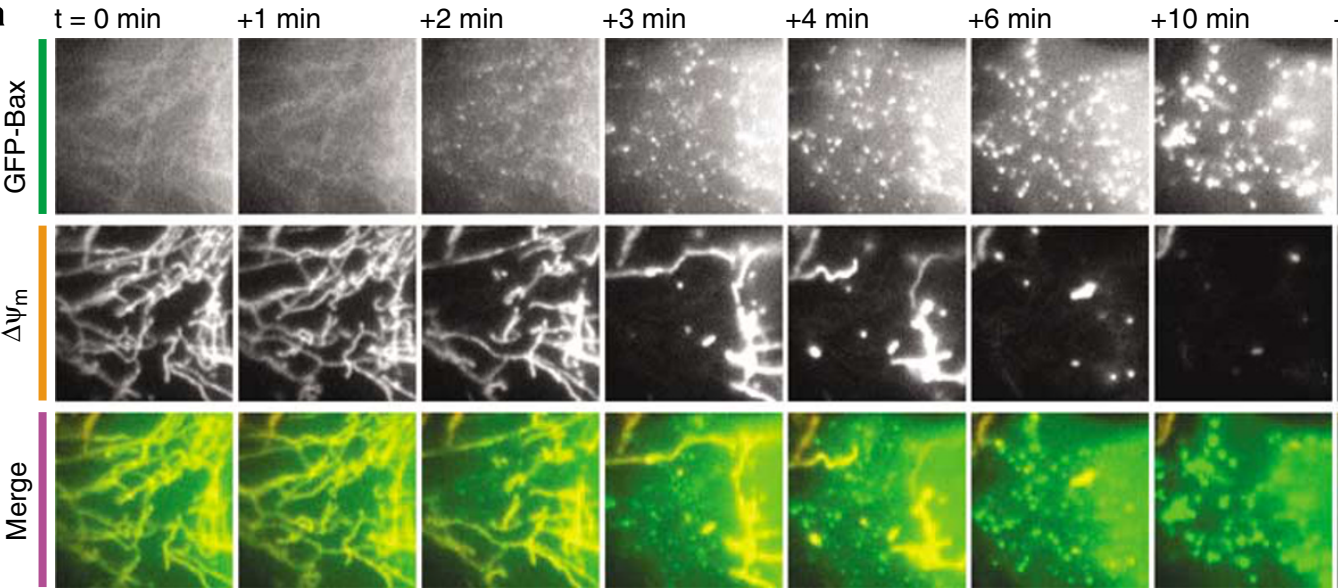

$+30 \min$
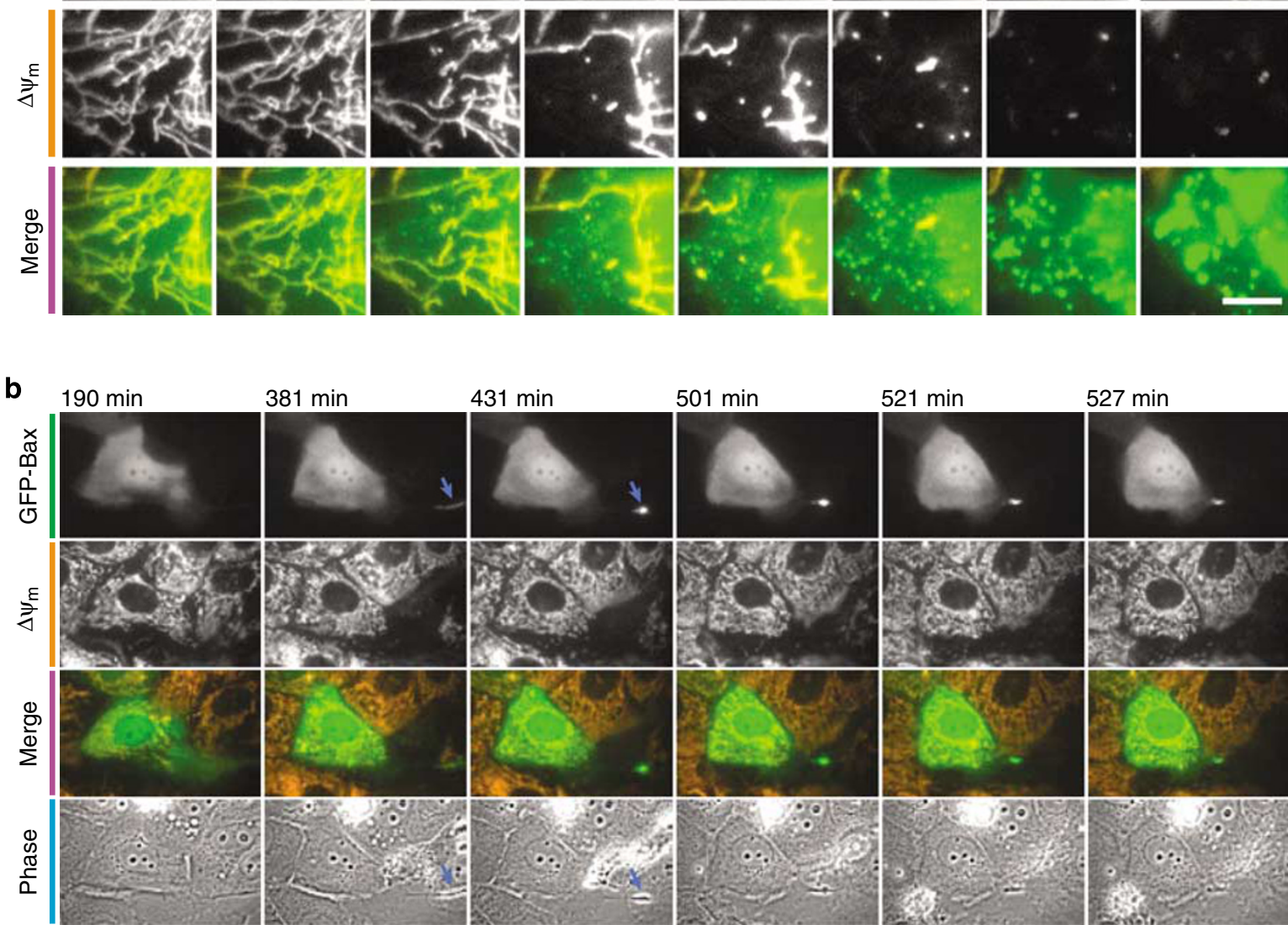

$431 \mathrm{~min}$

$501 \mathrm{~min}$

$521 \mathrm{~min}$

527 min

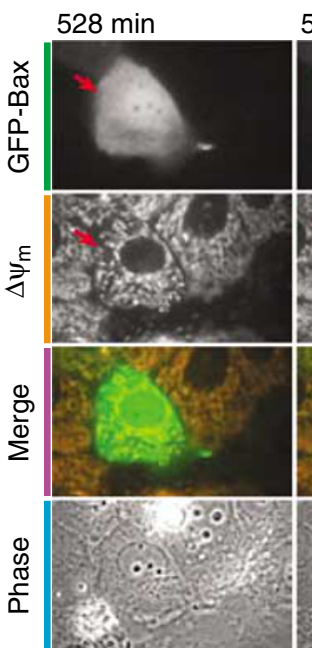

$529 \mathrm{~min}$
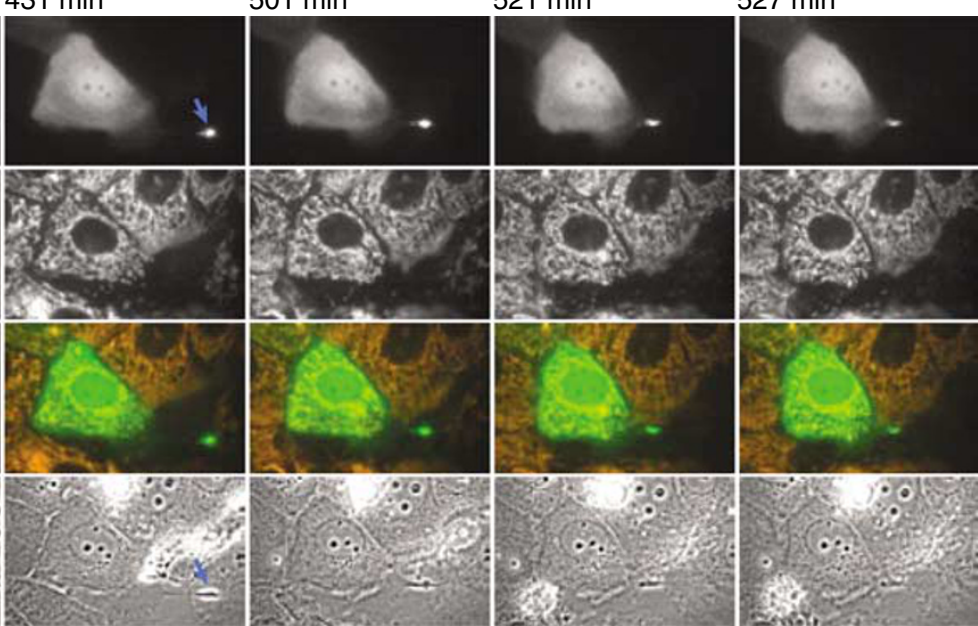

$530 \mathrm{~min}$

$535 \mathrm{~min}$

$540 \mathrm{~min}$

$560 \mathrm{~min}$
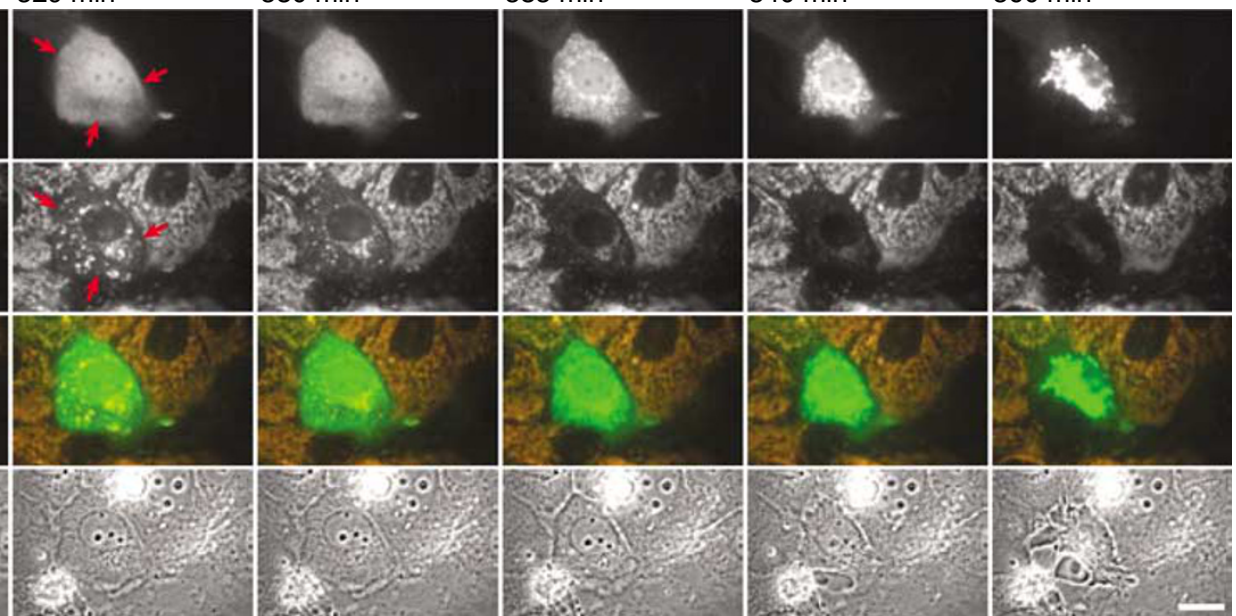

Figure 1 The onset of Bax activation and mitochondrial dysfunction is sudden but mitochondria show heterogeneity in loss of $\Delta \psi_{\mathrm{m}}$. (a) Upon GFP-Bax activation, U20S cells show heterogeneity in loss of $\Delta \psi_{\mathrm{m}}$. U2OS cells were transfected with GFP-Bax, loaded with TMRE to visualize $\Delta \psi_{\mathrm{m}}$ and treated with UV irradiation. $t=0$ represents $\sim 5 \mathrm{~h}$ following the UV irradiation. The complete sequence of images from which this figure is compiled is shown in Supplementary Videos $1-3$. Scale bar $10 \mu \mathrm{m}$. (b) Bax activation in one part of the cell rapidly triggers activation in an adjacent subcellular region. MCF10A cells were treated as described in (a). GFP-Bax first becomes active and forms bright foci in a small peripheral region ( $381 / 431 \mathrm{~min}$, blue arrows). When this region contacts the main cell body activation of the remaining GFP-Bax and loss of $\Delta \psi_{\mathrm{m}}$ is rapidly triggered (528/529 min, red arrows). The complete sequence of images from which this figure is compiled is shown in Supplementary Video 4 . Scale bar $10 \mu \mathrm{m}$ 
a

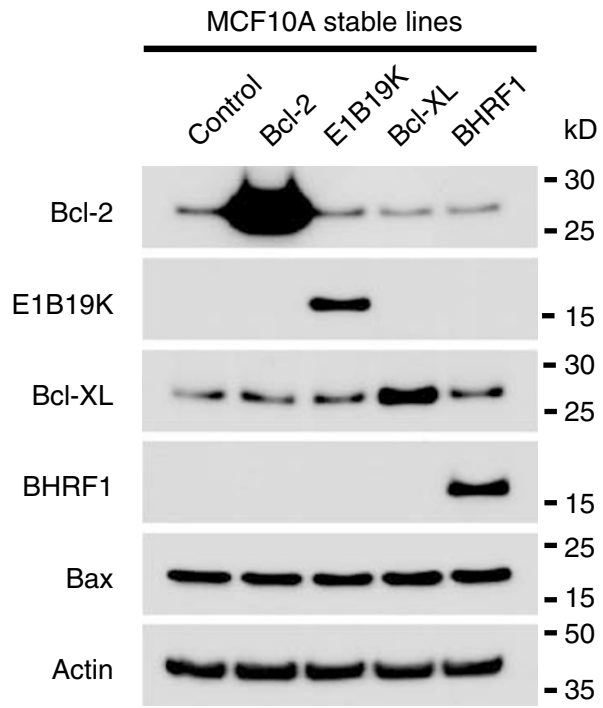

b

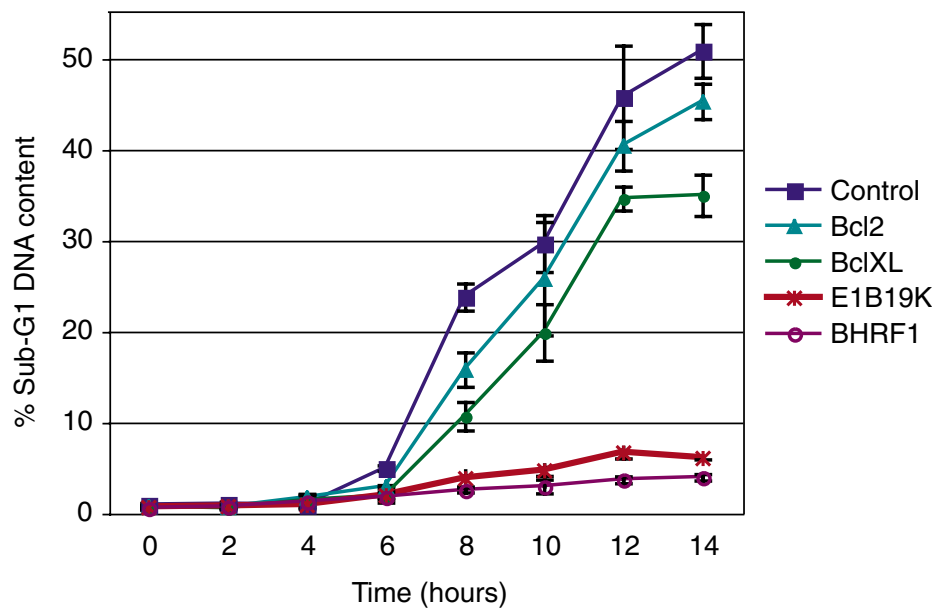

c

Control

kD $\quad \begin{array}{llllll}0 & 3 & 6 & 9 & 12 & 15\end{array}$

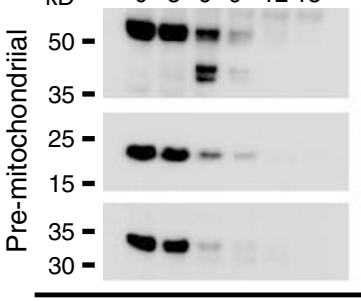

Bcl-2

$\begin{array}{lllll}0 & 3 & 6 & 9 & 1215\end{array}$

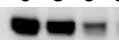

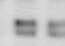

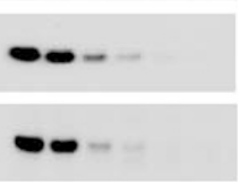

E1B19K

$\begin{array}{lllll}0 & 3 & 6 & 9 & 1215\end{array}$
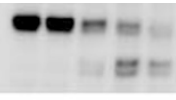

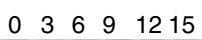
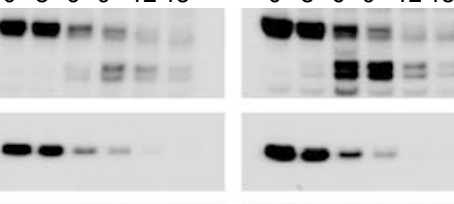

$\infty-$
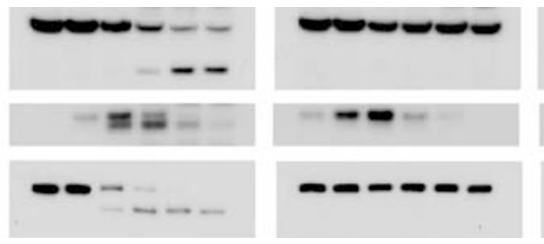

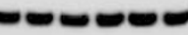

BHRF1

$\begin{array}{lllllll}0 & 3 & 6 & 9 & 12 & 15 & \text { Time (hours) }\end{array}$

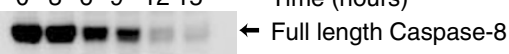

$\mathbf{u} \mathbf{z}=\mathbb{E}$ Cleaved Caspase-8

- - $\leftarrow$ Full length Bid

$\leftarrow$ Full length Caspase-3

Figure 2 Viral pro-survival proteins strongly protect MCF10A cells from FasL/CHX-induced apoptosis at the level of mitochondria. (a) Stable MCF10A cell lines were generated by retroviral transduction of the pro-survival proteins E1B19K, BHRF1, Bcl-2 and Bcl-XL. The empty retroviral vector was used as a control. (b) Viral pro-survival proteins strongly protect cells against FasL/CHX-induced apoptosis in comparison with overexpressed cellular Bcl-2 family proteins or control cells. MCF10A cells were treated with FasL/CHX over a $14 \mathrm{~h}$ time course and the percentage of cells with fragmented (sub-G1) DNA content was measured by FACS. (c) Events downstream of death receptor activation, but upstream of mitochondria, occur at the same rate in all cell lines, while events downstream of mitochondria are strongly inhibited in the cells expressing the viral pro-survival proteins E1B19K and BHRF1. Whole cell lysates from cells shown in (b) were analyzed by western blotting with antibodies specific for: Caspase 8, Bid, the pro-form of Caspase 3, Caspase 9, p17/p20 Caspase 3 and PARP. Actin is shown as a loading control

We next sought to determine the Bax activation status in cells protected by the viral pro-survival proteins. Antibodies raised again the $\mathrm{N}$-terminus of Bax and Bak are conformationally sensitive and recognize only the active form of the proteins. ${ }^{2,3}$ Cells were treated with FasL/CHX and Bax activation was assessed by immunoprecipitation using a conformationally sensitive anti-Bax N20 antibody. In control cells Bax becomes active and coimmunoprecipitates Bak, indicating the formation of Bax/Bak heterodimers and heteroligomers, whereas in cells expressing BHRF1 Bax conformational change was blocked and Bax failed to immunoprecipitate (Figure 3a). Strikingly E1B19K-expressing cells showed significant conformational activation of Bax, but with minimal coassociation of Bak, indicating that Bax/Bak oligomerization may be blocked (Figure 3a). Immunofluorescence analysis of FasL/CHX treated cells using the same Bax antibody and an antibody against Cyt- $c$ showed many control cells exhibited bright foci indicative of active Bax and associated release of Cyt- $c$ while BHRF1-expressing cells did not stain for active Bax (Figure 3b). In E1B19K-expressing cells, Bax was recognized by the $\mathrm{N} 20$ antibody but showed an even mitochondrial distribution and was not localized into punctate foci characteristic of fully active Bax. Cyt- $c$ retained a mitochondrial distribution in E1B19K- and BHRF1-expressing 
a
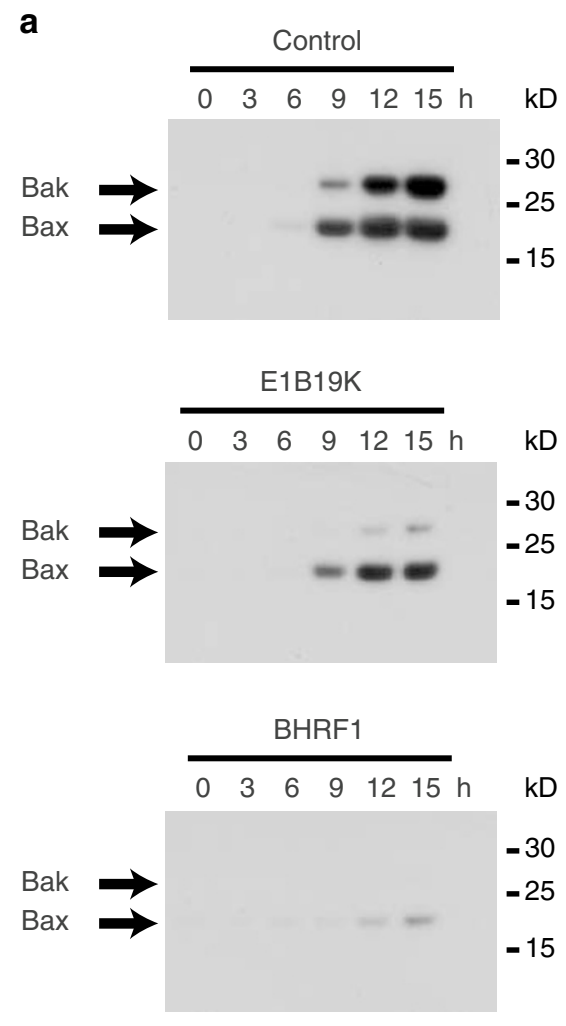

b
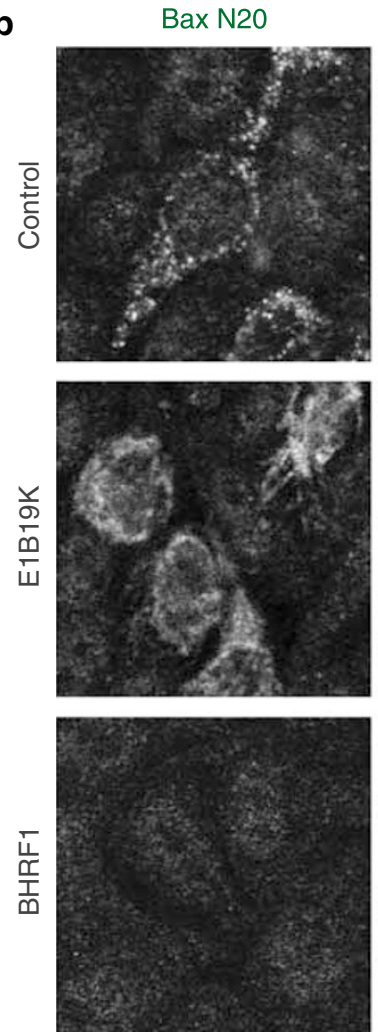
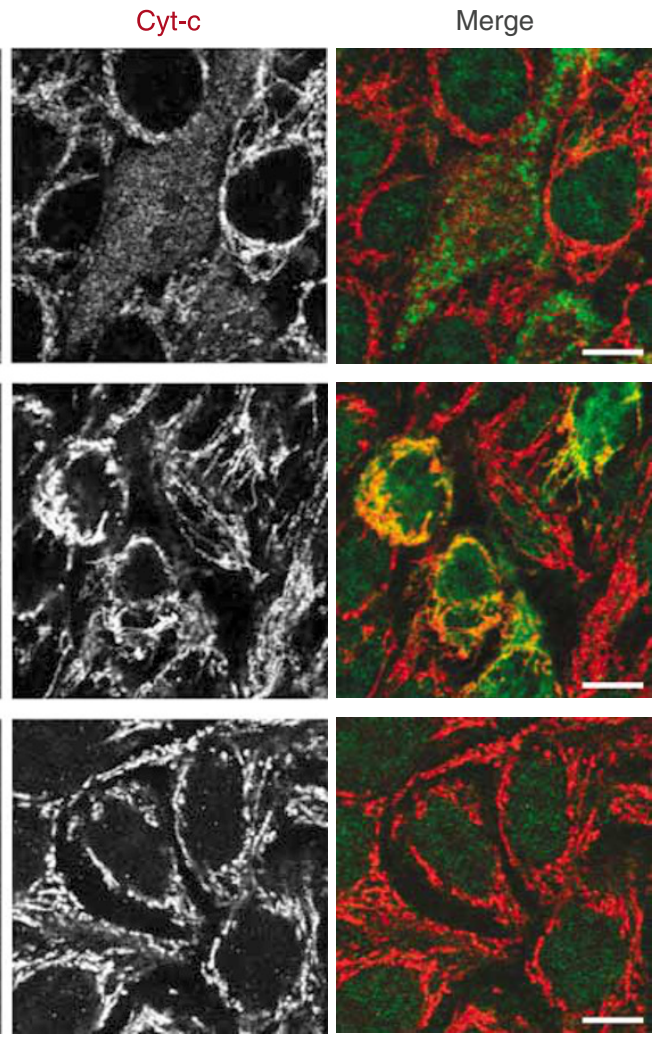

C

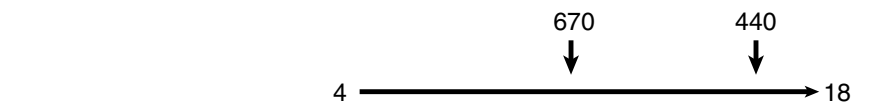

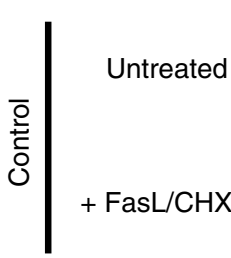

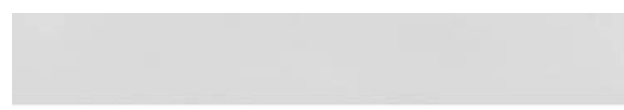

$19 \stackrel{158}{\downarrow}$
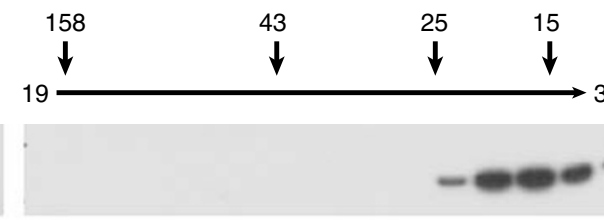

Size (kD) 33 Fraction
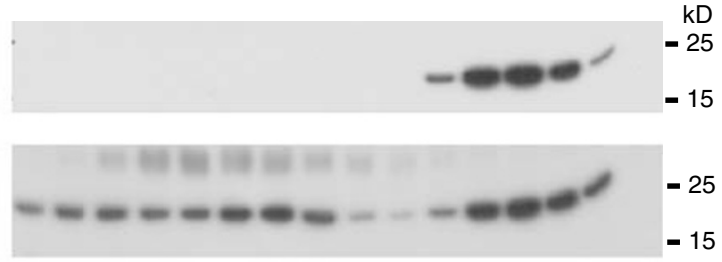

\begin{tabular}{l|r}
$\frac{\text { के }}{\frac{\Phi}{\omega}}$ & \\
& Intreated
\end{tabular}
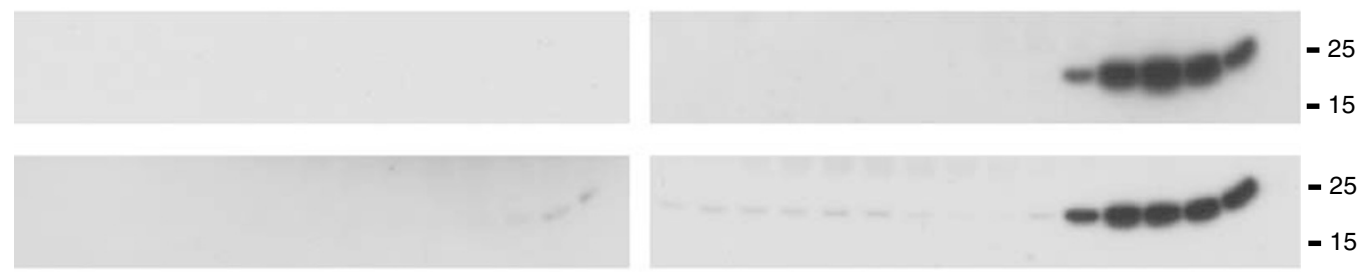

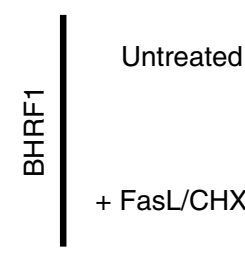

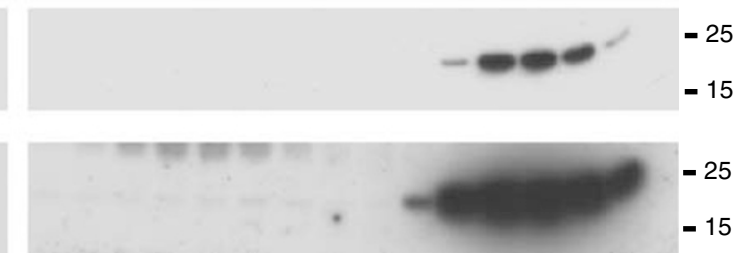

Figure 3 Viral pro-survival proteins separate stages in Bax activation. (a) BHRF1 prevents Bax conformational activation while E1B19 K prevents Bax association with Bak, but not Bax conformational activation. Bax was immunoprecipitated from MCF10A lysates following FasL/CHX treatment using the conformationally sensitive antibody Bax N20. Eluates were analyzed by western blotting for amount of active Bax and for coimmunoprecipitating Bak to assess whether Bax/Bak heterodimerization had occurred. (b) EIB19 K allows conformationally active Bax to accumulate at mitochondria whereas BHRF1 prevents detectable Bax activation. MCF10A cells were treated with FasL/CHX for $9 \mathrm{~h}$ were analyzed by immunofluorescence using anti-Bax N20 and anti-Cyt-c antibodies. Merged images are also shown. Scale bar $10 \mu \mathrm{m}$. (c) Both E1B19 K and BHRF1 prevent Bax from entering high molecular weight complexes. MCF10A cell lines were treated with Fas/CHX for $9 \mathrm{~h}$ and cell lysates separated by size exclusion chromatography. Selected fractions were analyzed by western blotting for Bax 
cells (Figure 3b). Similar results were obtained using UV irradiation to induce apoptosis in MCF10A cells and in U2OS osteosarcoma cells and IMR90 primary human fibroblasts stably expressing E1B19K and BHRF1 (data not shown). The proportion of MCF10A cells staining with anti-Bax N20 increased with the duration of FasL/CHX treatment, with most E1B19K-expressing cells staining positive for active Bax but without Cyt- $c$ release after $12 \mathrm{~h}$, correlating with maximum Bax activation as detected by immunoprecipitation (Figure 3a and data not shown). To confirm that Bax oligomerization was indeed blocked in the E1B19K- and BHRF1-expressing cells and these results were not due to masking of the N20 epitope, lysates were analyzed by size exclusion chromatography for the molecular weight distribution of total Bax. Bax moves into a high molecular weight range in control cells treated with FasL/CHX, and both viral proteins prevented this shift (Figure 3c).

Unlike Bax, Bak is constitutively localized to the mitochondria and therefore Bak activation does not require translocation. Bak also exhibits an N-terminal conformational change and coimmunostaining of Fas/CHX-treated cells with anti-Bak NT and anti-Cyt- $c$ revealed that Bak activation was blocked in an analogous manner to Bax; in control cells Bak activation was clearly associated with the formation of bright Bak foci, this occurred stochastically throughout the cell population and correlated with the release of Cyt- $c$ (Figure 4). In BHRF1expressing cells there was no evidence of Bak activation after $9 \mathrm{~h}$ of $\mathrm{Fas} / \mathrm{CHX}$ treatment, while E1B19K-expressing cells were recognized by the Bak NT antibody but with Bak evenly distributed over the mitochondrial network with no evidence of entry into bright foci or Cyt- $c$ release (Figure 4).
Together, these results demonstrate that expression of BHRF1 strongly inhibits Bax and Bak activation in response to FasL/CHX treatment, but not upstream apoptotic signaling events. E1B19K expression permits the initial $\mathrm{N}$-terminal conformational activation of both Bax and Bak, in agreement with previously published results, ${ }^{12,19-21}$ indicating the apoptotic signal reaches these molecules intact and at approximately the same rate as control cells; however, conformationally active Bax becomes blocked, evenly distributed on the mitochondrial network and fails to form foci or cause the release of Cyt- $c$.

We next sought to investigate the mechanism by which the viral pro-survival proteins block Bax/Bak activation. The direct binding of E1B19K to N-terminally active Bax can be detected by coimmunoprecipitation (Figure $5 \mathrm{a}$ ). In addition, an epitope within the $\alpha 7 / \alpha 8(\mathrm{BH} 2)$ region of Bax is masked in $\mathrm{E} 1 \mathrm{~B} 19 \mathrm{~K}-$ expressing cells following FasL/CHX treatment, as has been previously reported. ${ }^{20}$ This could indicate a second conformational change in this region is required for full Bax activation and is prevented by $\mathrm{E} 1 \mathrm{~B} 19 \mathrm{~K}$, or that this region is masked by direct interaction with E1B19K. At present these possibilities cannot be distinguished. BHRF1 limits Bax activation and strongly suppresses both Bak activation and the coassociation of Bax and Bak (Figure 5b). The anti-Bak NT antibody constitutively recognizes a small pool of Bak, even in untreated cells. BHRF1 coimmunoprecipitates with this Bak and the interaction is increased upon FasL/CHX treatment and could therefore explain how BHRF1 prevents Bak activation. The amount of BHRF1 associated with Bax is much lower and unlikely to fully explain the lack of Bax activation in these cells. In addition, we have observed
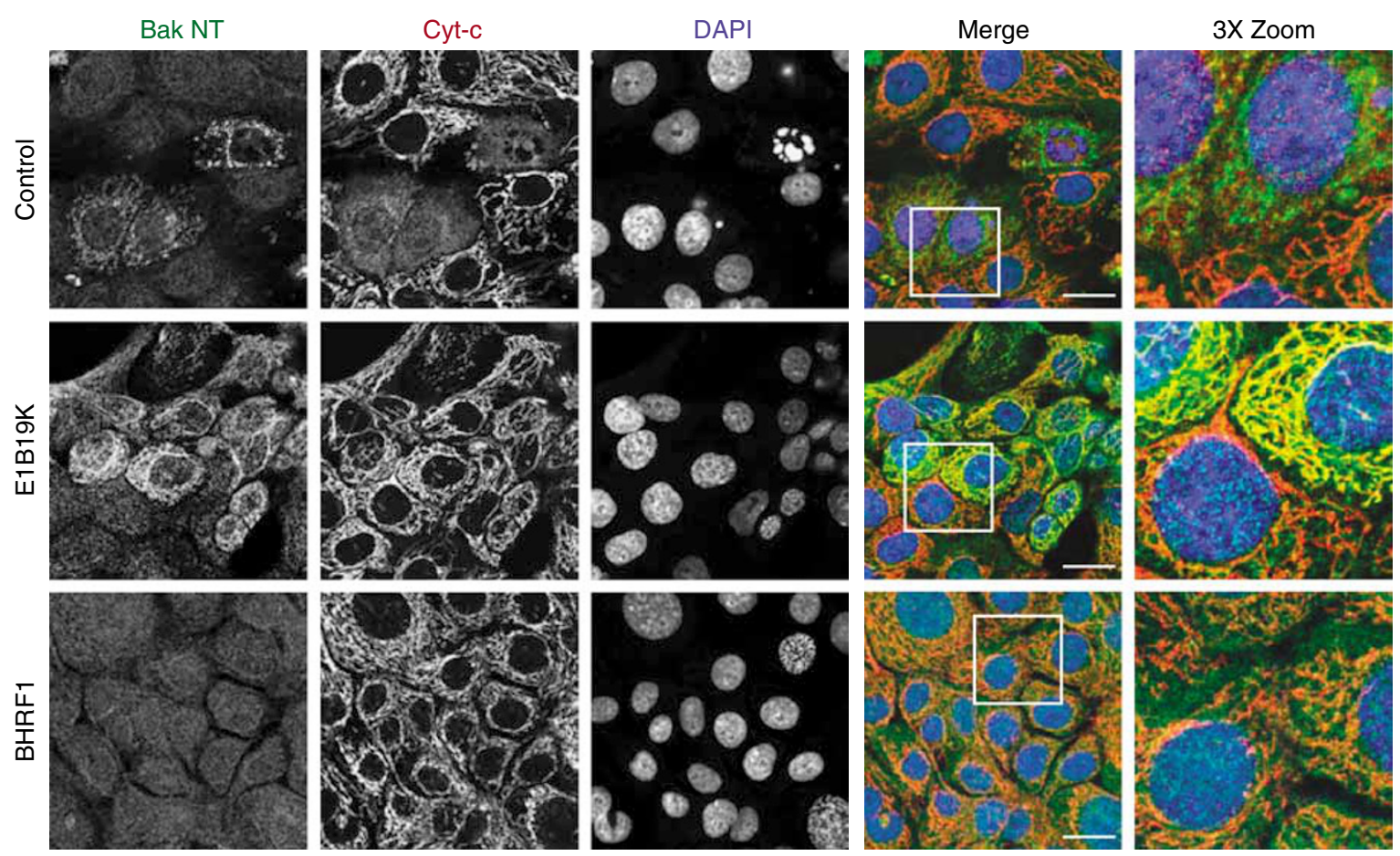

Figure 4 Bak activation is also blocked by E1B19K and BHRF1, but at separate stages. MCF10A cell lines were treated with FasL/CHX for $9 \mathrm{~h}$ and analyzed by immunofluorescence using conformationally sensitive anti-Bak NT and anti-Cyt-c antibodies, merged images are also shown with a $\times 3$ enlargement of the indicated area. Scale bar $20 \mu \mathrm{m}$ 

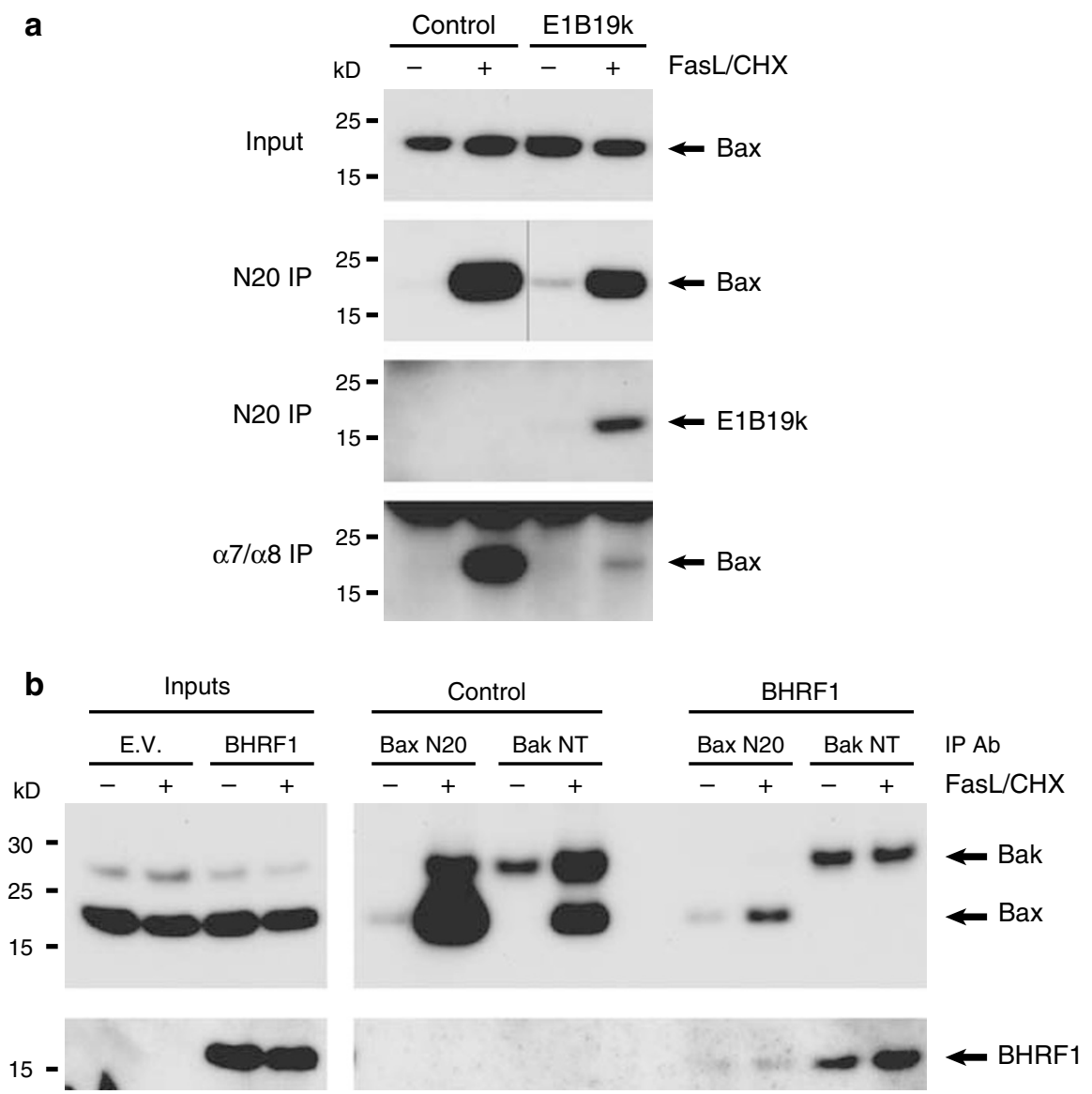

Figure 5 E1B19K interacts with active Bax and BHRF1 interaction with N-terminally active Bak is enhanced by FasL/CHX treatment. (a) Immunoprecipitation of active Bax from control and E1B19K-expressing cells shows E1B19K coimmunoprecipitates with active Bax following FasL/CHX treatment. E1B19K expression also masks exposure of an $\alpha 7 / \alpha 8$ (BH2-domain) epitope within Bax following FasL/CHX treatment. (b) Immunoprecipitation of active Bax and Bak from control and BHRF1-expressing cells shows BHRF1 reduces activation and prevents oligomerization of both Bax and Bak in response to FasL/CHX. BHRF1 coimmunoprecipitates with Bak, but not active Bax, and this interaction is enhanced by FasL/CHX treatment

GFP-Bax remains cytoplasmic in BHRF1 expressing cells following FasL/CHX treatment, while BHRF1 is localized to mitochondria (our unpublished observations), also suggesting it is less likely BHRF1 blocks Bax activation by direct interaction. It is possible BHRF1 protects by binding and sequestering the tBid generated in response to FasL/CHX, but we have been unable to detect Bid or tBid in BHRF1 immunoprecipitations (data not shown). Therefore, BHRF1 can bind and inhibit Bak activation but further work is required to determine how BHRF1 inhibits Bax activation.

Electron microscopy can be used to visualize ultrastructural changes occurring within individual mitochondria but it is difficult to identify cells undergoing the earliest stages of Bax activation due to the asynchronous initiation and rapid progression of this process. We reasoned that the viral proteins characterized above provided an ideal way to accumulate entire populations of cells in which Bax activation was blocked at different stages, and thereby to analyze whether changes in mitochondrial ultrastructure could occur prior to Bax activation. MCF10A cells were therefore treated with FasL/CHX for $12 \mathrm{~h}$ and then fixed and stained for EM. Ultrastructural analysis performed in situ eliminates the danger of changes caused by purification of the mitochondria and therefore more clearly demonstrates changes preexisting in cells before Bax and Bak activation. Changes in the mitochondrial ultrastructure of control cells undergoing apoptosis in response to FasL/CHX were clearly detectable (Figure 6a) and were categorized according to the degree of matrix condensation and remodeling of cristae membranes (Figure 6b). We also noticed the appearance of electron dense granules in the matrix of mitochondria following treatment with FasL/CHX that have been reported previously as precipitates of calcium phosphate ${ }^{28}$ and have been shown to be reversible in neuronal samples following periods of stimulation. ${ }^{29}$ The presence of electron dense granules in the present study suggests there has been significant mitochondrial $\mathrm{Ca}^{2+}$ uptake.

After $12 \mathrm{~h}$ FasL/CHX treatment there was significant apoptosis in wild type cells, but little detectable cell death in either E1B19K- or BHRF1-expressing populations, although by this time most E1B19K cells have accumulated conformationally active Bax at mitochondria (Figure 7a). Ultrastructural analysis revealed significant remodeling of mitochondria in control cells from Type I to Type Ila/b morphologies (Figure 7b). Remodeling had also taken place in E1B19Kand BHRF1-expressing cells, independently of the stage of 
a Type I:

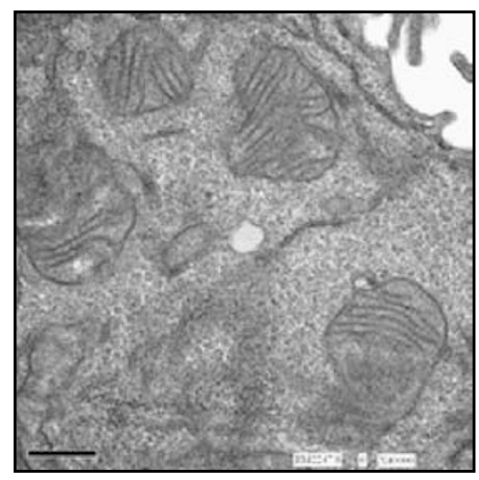

Type Ila:

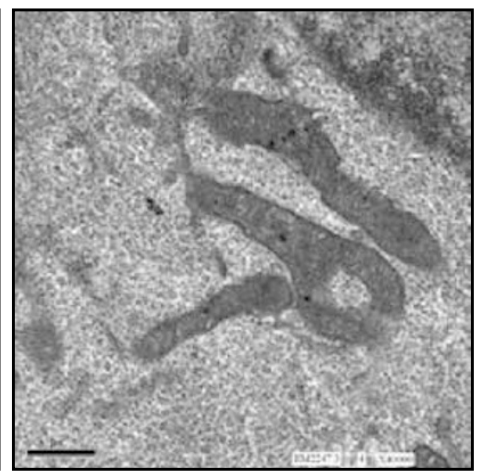

Type Ilb:

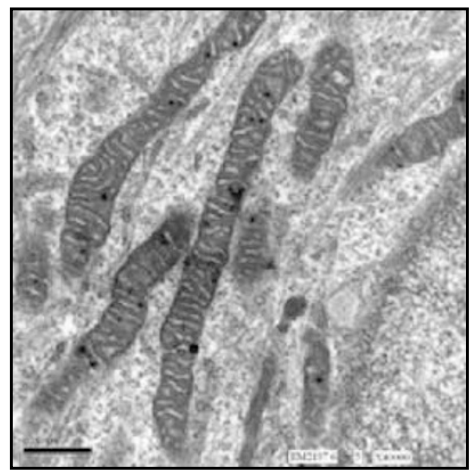

b Type I:
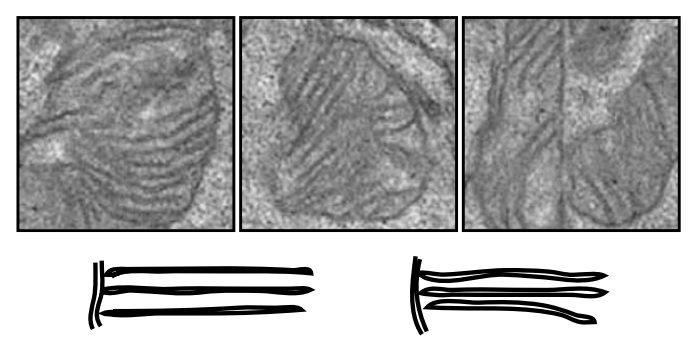

Type IIb:
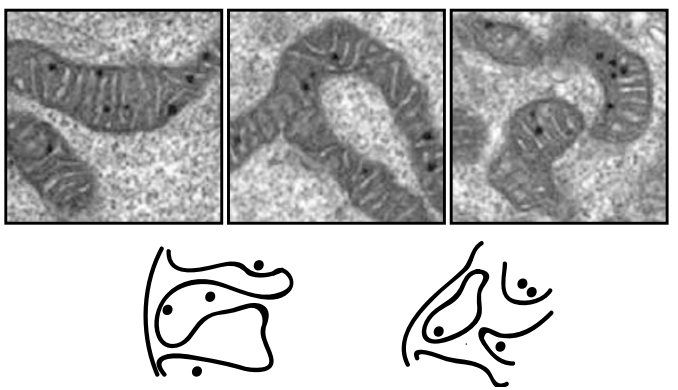

Type Ila:

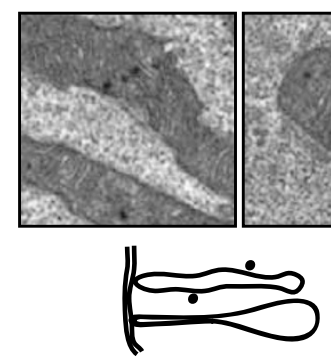

Type III:
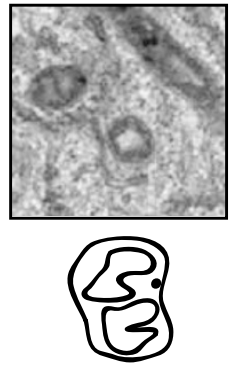

Figure 6 Changes in mitochondrial ultrastructure occur during apoptosis. (a) Electron micrographs of mitochondria in MCF10A control cells treated with or without FasL/ $\mathrm{CHX}$ for $12 \mathrm{~h}$. Scale bar $0.5 \mu \mathrm{m}$. (b) Mitochondrial ultrastructural changes were categorized according to degree of cristae remodeling as shown. Scheme adapted from Scorrano L. ${ }^{27}$ Electron dense granules appearing in the matrix space are also shown

Bax and Bak activation (Figure 7b), clearly demonstrating that changes in mitochondrial ultrastructure can precede Bax and Bak activation.

In some systems fragmentation of the mitochondrial network has been observed during apoptosis. In the present study, widespread mitochondrial fragmentation preceding Cyt- $c$ release was not apparent by confocal microscopy and quantification of the number of mitochondria per electron micrograph revealed a modest increase in the number of mitochondria per frame following FasL/CHX treatment (Figure 7c). The presence of electron dense granules in the mitochondrial matrix was also quantified and revealed a dramatic increase following treatment with FasL/CHX (Figure 7d), suggesting significant $\mathrm{Ca}^{2+}$ uptake by mitochondria in response to the FasL/CHX treatment. Importantly, both phenomena occurred in all cell lines regardless of Bax/Bak activation status, thereby providing additional evidence that mitochondria can respond to the stress of an apoptotic stimulus prior to the activation of Bax and Bak.

\section{Discussion}

Bax and Bak are responsible for mitochondrial dysfunction during apoptosis and it is widely assumed that changes in mitochondria occurring during apoptotic cell death are therefore a result of Bax and Bak activation. Bax becomes active in the plane of mitochondrial membranes ${ }^{30}$ and Bax can pre-exist at mitochondrial membranes without inducing apoptosis. ${ }^{2}$ Since mitochondrial localization of at least a fraction of the total cellular Bax does not guarantee activation, further events must be necessary. This could involve the insertion of the central helical core of Bax into the membrane to initiate Bax oligomerization. ${ }^{31}$ It is also possible that mitochondria 
a

$12 \mathrm{~h}$ FasL/CHX

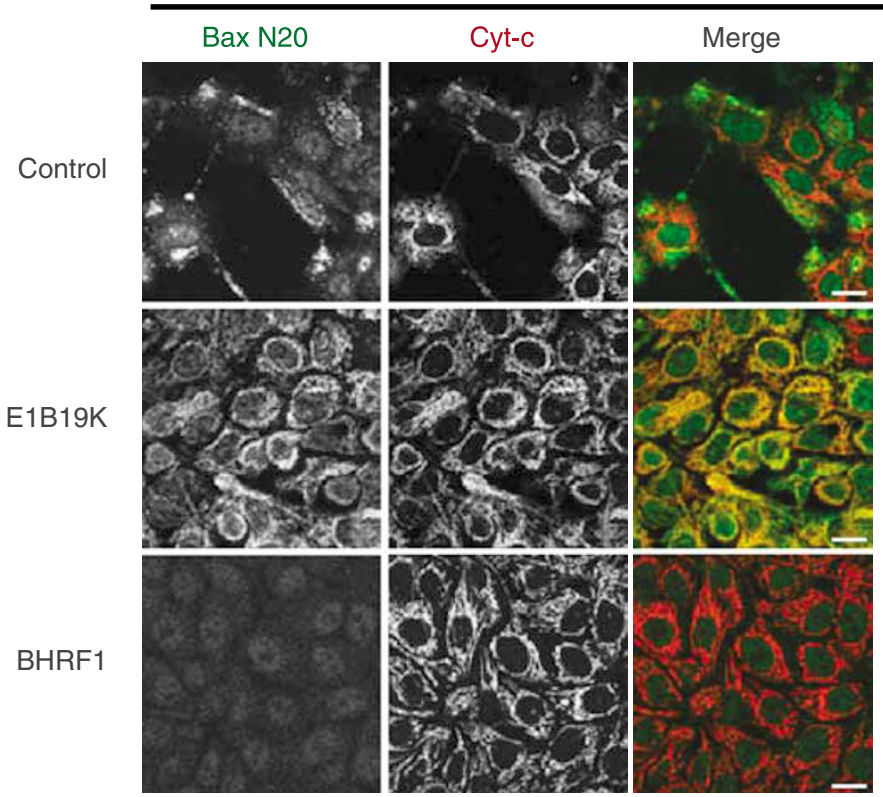

b

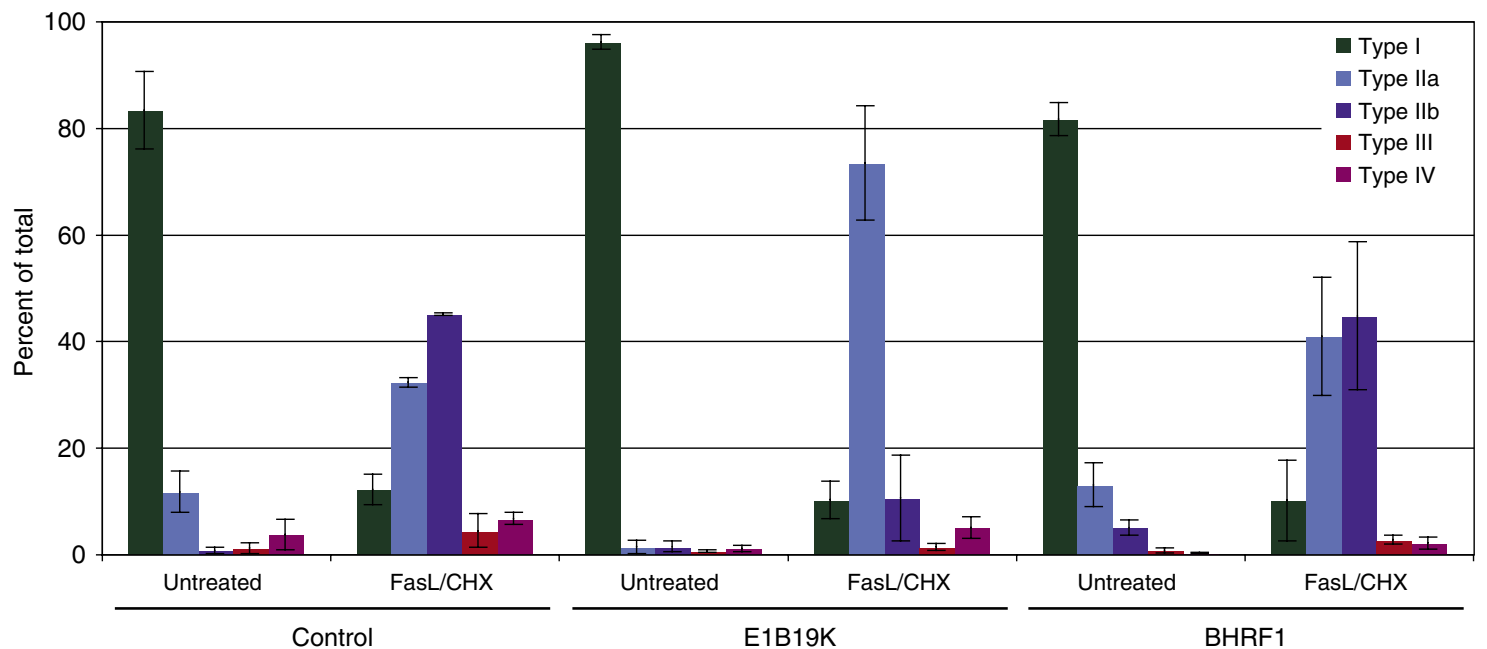

C

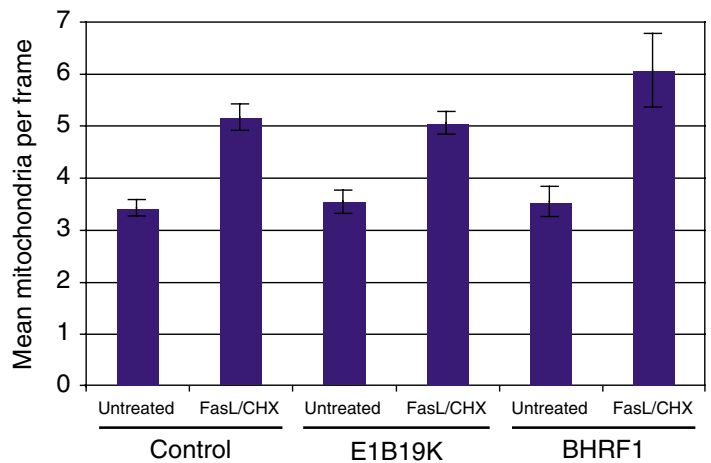

d

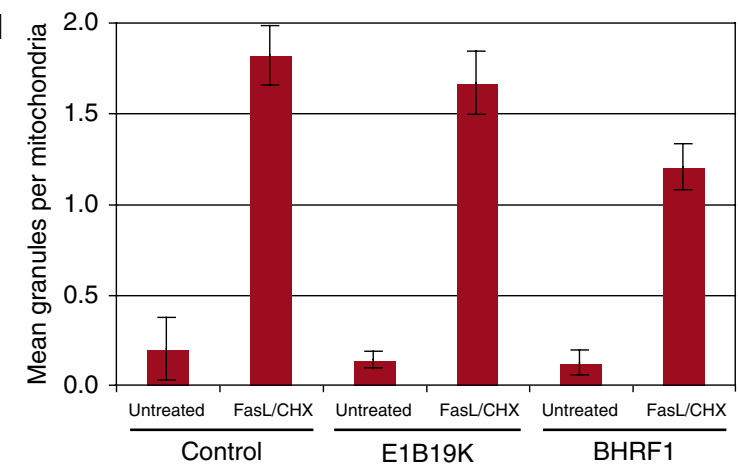

Figure 7 Changes in mitochondrial ultrastructure occur independently of Bax activation. (a) Immunofluorescence analysis with anti-Bax N20 and anti-Cyt-c reveals that after $12 \mathrm{~h}$ FasL/CHX treatment control cells are undergoing significant apoptosis while BHRF1-expressing cells lack detectable Bax activation or Cyt-c release. Most E1B19Kexpressing cells stain positive for N-terminally active Bax but fail to show bright foci characteristic of full active Bax or release of Cyt-c. Scale bar $20 \mu \mathrm{m}$. (b) Mitochondrial ultrastructural remodeling occurs in all MCF10A cell lines, regardless of whether Bax activation is prevented (BHRF1) or blocked following initial conformational activation (E1B19K). Results show mean \pm 1 S.E. for three independent experiments. In each experiment all mitochondria from at least 20 micrographs, each representing a different cell, were scored for cristae morphology according to the scheme outlined in Figure 5. (c) Modest fragmentation of the mitochondrial network occurs in all cell lines following FasL/CHX treatment. Results show mean \pm 1 S.E. for the number of mitochondria per electron micrograph scored in part (b). (d) Electron dense granules appear in the mitochondrial matrix in all cell lines following FasL/CHX treatment. Results show mean \pm 1 S.E. for the number of electron dense granules per mitochondria scored in part (b) 


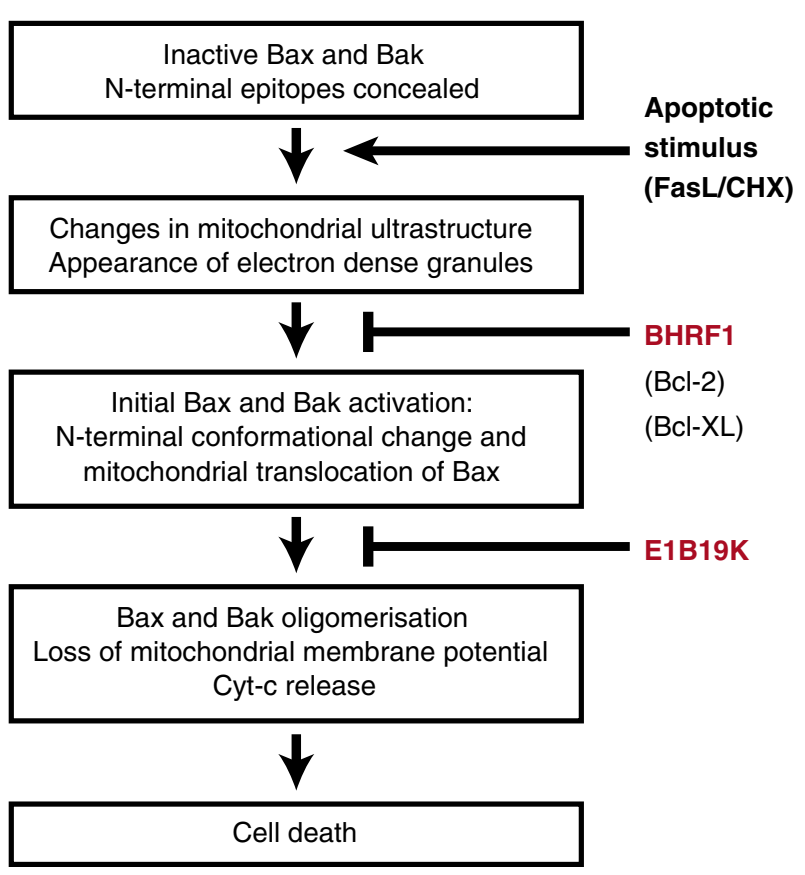

Figure 8 Model for Bax and Bak activation during apoptosis. Viral proteins E1B19K and BHRF1 can be used to separate stages in Bax and Bak activation and reveal that changes in mitochondrial ultrastructur can precede Bax and Bak activation

respond to the stress of an apoptotic insult prior to cell-wide Bax activation and could directly participate in Bax activation.

In the present study, inactivation of Bax and Bak at different steps in the apoptotic program using the viral proteins E1B19K and BHRF1 reveals that changes in mitochondrial ultrastructure can occur independently of Bax and Bak activation (Figure 8). E1B19K acts after the initial conformational activation of both Bax and Bak, and mitochondrial recruitment of Bax, by direct binding to prevent Bax/Bak oligomerization. ${ }^{12,19-21}$ E1B19K therefore allows an activating signal to reach $\mathrm{Bax}$ and Bak intact and then blocks cell death by preventing their oligomerization - this may be an efficient step for a viral protein to target, at a point where diverse apoptotic stimuli converge. BHRF1 appears to act earlier, also preventing the $\mathrm{N}$-terminal activation of Bax and Bak. BHRF1 binds Bak and this interaction increases following treatment with $\mathrm{FasL} / \mathrm{CHX}$, without an increase in Bak N-terminal activation, in this respect BHRF1 may function in an analogous fashion to $\mathrm{Bcl}-\mathrm{XL}$ and $\mathrm{Mcl}-1 .{ }^{8}$ However, these data do not explain how mitochondrial BHRF1 can prevent activation of cytoplasmic Bax. BHRF1 has a less prominent hydrophobic groove for binding $\mathrm{BH}$-only members ${ }^{32}$ and despite being an extremely potent suppressor of Bax/Bak activation, it shows a limited selectivity for $\mathrm{BH}$-only peptides in vitro. ${ }^{33}$ Therefore, these data do not exclude BHRF1mediating a protective effect through additional as yet unidentified targets at the mitochondria.

The majority of Cyt- $c$ is sequestered in the cristae cisternae and tightly associated with cardiolipin ${ }^{34}$ and tBid can induce remodeling of mitochondrial cristae in the absence of Bax and Bak necessary for complete release of Cyt- $c$ during apoptosis. ${ }^{27}$ tBid may contribute to the ultrastructural changes observed in the present study as tBid is generated downstream of death receptor activation in both E1B19K- and BHRF1-expressing cells, at levels comparable to that seen in control cells (Figure 2c). However, there are likely to be multiple pathways communicating pro-apoptotic signals to mitochondria, for example, BIK, another BH3-only protein, can induce cristae remodeling mediated by a $\mathrm{Ca}^{2+}$-dependent mechanism. ${ }^{35}$ Interestingly, electron dense granules, thought to be calcium phosphate precipitates, appear in the mitochondrial matrix of FasL/CHX-treated cells regardless of whether Bax/Bak activation has occurred. There are emerging roles for $\mathrm{Bcl}-2$ family proteins in directly modulating $\mathrm{ER}$ $\mathrm{Ca}^{2+}$ dynamics ${ }^{36}$ and $\mathrm{Ca}^{2+}$ release from intracellular ER stores is known to occur during cellular bioenergetic stress and can act to upregulate energy conserving pathways and ATP production. ${ }^{37}$ In addition, mitochondria avidly uptake cytosolic $\mathrm{Ca}^{2+}$, upregulating the activity of key mitochondrial dehydrogenases, oxidative metabolism and ATP production. ${ }^{38}$ The ability of mitochondria to buffer free $\mathrm{Ca}^{2+}$ can be exceeded promoting mitochondrial permeability transition and thereby apoptosis when release of accumulated $\mathrm{Ca}^{2+}$ could result in a feed-forward loop ensuring coordinated recruitment of other mitochondria within the cell. Both inter- and intramitochondrial $\mathrm{Ca}^{2+}$ waves have been observed during apoptotic cell death ${ }^{39}$ and can be modified by the degree of fragmentation of the mitochondrial network. ${ }^{40}$ In the future it will be important to understand how Bcl-2 pro-survival proteins allow mitochondrial physiological responses to stress to occur, without triggering Bax/Bak activation.

Changes in metabolism have been correlated with changes in mitochondrial ultrastructure, with more condensed matrix and swollen cristae spaces generally indicating more active (ADP-stimulated) oxidative phosphorylation. ${ }^{22-24,26}$ Here, we observe similar changes in apoptotic cells fixed and stained in situ; there is a striking resemblance between the transition from Type I to Type II mitochondria during apoptosis and the transition of mitochondria from 'orthodox' to 'condensed' morphology observed during metabolic stimulation. These phenomena could be related to upregulation of mitochondrial metabolism and oxidative phosphorylation to provide additional ATP and metabolic intermediates to help combat stress or damage associated with a pro-apoptotic stimulus. Perhaps the duration or extent of the cellular insult, combined with the extent of pro-survival response the cell can mount, is involved in determining whether survival is possible or the cell should commit to apoptosis. If mitochondria respond to cell stress before Bax/Bak activation commits the cell to apoptosis, it raises the possibility of 'inside-out' signaling from mitochondria to Bcl-2 family proteins. Viral proteins can act as important tools to delineate such pathways and better understand whether mitochondrial responses prior to Bax/Bak activation play an integrating role in processing pro-apoptotic stress. It could be that primitive adaptive mitochondrial responses to cell stress are now intercepted by $\mathrm{Bcl}-2$ proteins in higher eukaryotes, but further studies are necessary to clarify how mitochondria adapt to pro-apoptotic stress and clarify whether they participate in regulating the activity of $\mathrm{Bcl}-2$ family proteins. 


\section{Materials and Methods}

Cell lines and induction of apoptosis. U2OS osteosarcoma cells were grown in DMEM $+10 \%$ fetal bovine serum. MCF10A mammary epithelial cells were grown in Ham's nutrient mixture F-12/DMEM (1:1) supplemented with $5 \%$ horse serum and $10 \mu \mathrm{g} / \mathrm{ml}$ insulin, $20 \mathrm{ng} / \mathrm{ml} \mathrm{EGF,} 5 \mu \mathrm{g} / \mathrm{ml}$ hydrocortisone and $100 \mathrm{ng} / \mathrm{m}$ cholera toxin. For cell death treatments minimal medium supplemented with $5 \%$ horse serum was used. Retroviral constructs: pBABE puro Bcl-2, pBABE hygro $\mathrm{Bcl}-\mathrm{XL}$, pBABE puro E1B19K and $\mathrm{pBABE}$ puro BHRF1 were obtained from $\mathrm{D}$ Hancock, CR-UK and introduced by retroviral transduction. MCF10A cells were selected with $1 \mu \mathrm{g} / \mathrm{ml}$ puromycin or $300 \mu \mathrm{g} / \mathrm{ml}$ hygromycin B respectively and the presence of the transduced proteins was confirmed by western blotting using antiBcl-2 (Santa Cruz), anti-Bcl-XL (Transduction Labs), anti-E1B19K (Oncogene) and anti-BHRF1 (Chemicon) monoclonal antibodies. The resulting stable cell lines were used for all subsequent experiments in this study. For induction of apoptosis by UV irradiation cells were exposed to $30 \mathrm{~J} / \mathrm{m}^{2} \mathrm{UVC}$ in a UV crosslinker (Hoefer). For FasL/ $\mathrm{CHX}$ treatments anti-Fas IgM clone $\mathrm{CH} 11$ (Upstate) was used at a final concentration of $250 \mathrm{ng} / \mathrm{ml}$ with $2 \mu \mathrm{g} / \mathrm{ml} \mathrm{CHX}$.

Live cell video microscopy. For live cell microscopy the indicated cell lines were seeded in $35 \mathrm{~mm}$ glass bottomed dishes (MatTek). $24 \mathrm{~h}$ later cells were transfected with GFP-Bax (a gift from R Youle, NIH) using Effectene (Qiagen). After a further $24 \mathrm{~h}$, cells were loaded with $2 \mathrm{nM}$ tetramethylrhodamine methyl ester (TMRE, Molecular Probes) phenol red-free added to the growth media for $20 \mathrm{~min}$. Cells were washed and phenol red-free media added together with the indicated treatment to induce apoptosis. All time-lapse experiments were conducted on a Zeiss Axiovert 135 TV inverted microscope (Carl Zeiss) under the control of AQM image acquisition software (Kinetic Imaging). Filters and dichromatic mirrors were purchased from Omega Optical Inc. and permitted the detection of EGFP and TMRE. The microscope was housed in a purpose built Perspex environmental chamber maintained at $37^{\circ} \mathrm{C}$ using a heater unit constructed in-house (CR-UK Research Services). Images were collected using a CCD camera using $\times 63$ planapochromat Phase 3 oil-immersion objective, numerical aperture 1.4 (Carl Zeiss) at $1 \mathrm{~min}$ intervals for a total of 1000 cycles. Representative still frames were extracted from the record for illustrative purposes and the complete series of images was compiled into movie files.

FACS analysis for cells with sub-G1 DNA content. MCF10A cells were treated in triplicate with FasL/CHX as indicated to induce apoptosis and harvested by scraping into PBS. Cells were fixed with ice cold $70 \%$ ethanol, then washed twice in $0.2 \mathrm{M}$ disodium phosphate, $4 \mathrm{mM}$ citric acid, $\mathrm{pH} 7.8$ and treated with $50 \mu \mathrm{l}$ of $100 \mu \mathrm{g} / \mathrm{ml} \mathrm{RNase} \mathrm{followed} \mathrm{by} 200 \mu \mathrm{l}$ of $50 \mu \mathrm{g} / \mathrm{ml}$ propidium iodide (PI). Cells were then analyzed by FACS for DNA content. 10000 events were acquired and data analysis was preformed using FlowJo software (TreeStar Inc.).

Immunoprecipitation and western blotting. MCF10A cells were treated with FasL/CHX and lysed in 1\% CHAPS buffer: $50 \mathrm{mM}$ Tris- $\mathrm{HCl}, 150 \mathrm{mM}$ $\mathrm{NaCl}, 1 \%$ CHAPS, $2 \mathrm{mM}$ EDTA, $5 \%$ glycerol, $1 \times$ Complete protease inhibitors (Roche), pH 8.0. Lysates were clarified by centrifugation at $10000 \mathrm{~g}$ and $10 \%$ of the sample reserved for analysis by SDS-PAGE followed by western blotting with anti-caspase 8 1C12, anti-caspase 3 3G2, anti-active caspase 3, anti-caspase 9 (Cell Signaling Technology), anti-Bid (FL195, Santa Cruz) and anti-PARP (BD). Conformationally active Bax was immunoprecipitated with cell lysates using antiBax N20-coupled agarose beads (Santa Cruz) and anti-Bax $\alpha 7 / \alpha 8$, BH2 domain (Oncogene). Active Bak was immunoprecipitated with anti-Bak NT (Upstate). Immunoprecipitates were subjected to western blot analysis using anti-Bax 2D2 (Merck) and anti-Bak NT. Replicate samples from the same experiment were used for the cell viability analysis (Figure 2b) and IP/westerns (Figure 2c and $3 a$ ).

Immunofluorescence microscopy. MCF10A cells were seeded onto glass coverslips and $24 \mathrm{~h}$ later were treated with FasL/CHX as indicated. Cells were then fixed in $3 \%$ PFA, permeabilized with $0.1 \%$ Triton X-100, blocked with $0.2 \%$ fish skin gelatin and immunostained. Primary antibodies were anti-Cyt- $C(B D)$ and antiBax N20 (Santa Cruz). Secondary antibodies were Cy-3 conjugated anti-mouse IgG and FITC-conjugated anti-rabbit IgG (Jackson ImmunoResearch). Coverslips were mounted onto glass slides using ProLong anti-fade reagent (Molecular Probes) and imaged using a LSM510 confocal microscopy fitted with a $63 \mathrm{X} / 1.4$ plan-apochromat Phase 3 oil immersion objective (Carl Zeiss).
Size exclusion chromatography. MCF10A cells were harvested by scraping into PBS, pelleted at 2000 r.p.m. and lysed in an equal volume of $2 \%$ CHAPS lysis buffer (without glycerol). Following rotation at $4{ }^{\circ} \mathrm{C}$ for $20 \mathrm{~min}$, samples were clarified by spinning at $21000 \times \mathrm{g}$ for $20 \mathrm{~min}$ and $40 \mu \mathrm{l}$ loaded onto a preequilibrated Superdex 200 Precision Column PC $3.2 / 30$ (2.4 ml; Pharmacia). The column was calibrated using thyroglobulin $(667 \mathrm{kD})$, ferritin $(440 \mathrm{kD})$, aldolase $(158 \mathrm{kD})$, BSA $(67 \mathrm{kD})$, ovalbumin $(43 \mathrm{kD})$, chymotrypsinogen $\mathrm{A}(25 \mathrm{kD})$ and ribonuclease $A(14 \mathrm{kD})$. The entire column volume was collected in $40 \mu \mathrm{l}$ fractions and $10 \mu \mathrm{l}$ analyzed by SDS PAGE.

Electron microscopy. MCF10A cells were grown on Thermanox plastic coverslips (Agar scientific) and following induction of apoptosis cells were fixed in a modified Karnovsky's fixative (4\% paraformaldehyde, $2.5 \%$. glutaraldehyde, $2 \mathrm{mM}$ $\mathrm{CaCl}_{2}$ in $0.1 \mathrm{M} \mathrm{Na}$ cacodylate, $\mathrm{pH} 7.4$ ) and processed on the coverslips. Cells were washed in cacodylate buffer and post-fixed using 1\% osmium tetroxide, $1 \%$ potassium ferricyanide in $0.1 \mathrm{M} \mathrm{Na}$ cacodylate $\mathrm{pH} 7.4$. Cells were washed again and $2 \%$ aqueous uranyl acetate solution was added for contrast enhancement. Cells were washed and then dehydrated by processing through a graded series of ethanol and then propylene oxide and then left in infiltrate with 50/50 mixture of araldite/ propylene oxide overnight at room temperature. The next day infiltration was continued with $3 \times 1 \mathrm{~h}$ changes of araldite alone (the samples were warmed to $60^{\circ} \mathrm{C}$ for about $10 \mathrm{~min}$ before each change). Samples were then left to polymerize at $60^{\circ} \mathrm{C}$ overnight. Sections of $\sim 90 \mathrm{~nm}$ thickness were cut on a Leica Ultracut S Ultratome (Leica) and collected on 200-mesh copper grids. Sections were further stained with a saturated solution of uranyl acetate in methanol for $\sim 6 \mathrm{~min}$ at $\mathrm{RT}$, rinsed $4 \times$ in methanol and then with Reynold's lead citrate stain for 4 min RT and rinsed $4 \times$ in water. Samples were viewed in a JEOL 1200 TEM (JEOL). Each micrograph collected represented a different cell selected at random from the grid. At least 20 cells were examined in each sample and all mitochondria appearing in the micrographs were scored for ultrastructural morphology.

Acknowledgements. We thank Colin Gray for assistance with live cell video microscopy, Olga O'Neill for assistance with size exclusion chromatography and members of the Signal Transduction Laboratory for helpful comments and suggestions.

1. Danial NN, Korsmeyer SJ. Cell death: critical control points. Cell 2004; 116: 205-219.

2. Nechushtan A, Smith CL, Hsu YT, Youle RJ. Conformation of the Bax C-terminus regulates subcellular location and cell death. EMBO J 1999; 18: 2330-2341.

3. Griffiths GJ, Dubrez L, Morgan CP, Jones NA, Whitehouse J, Corfe BM et al. Cell damageinduced conformational changes of the pro-apoptotic protein Bak in vivo precede the onset of apoptosis. J Cell Biol 1999; 144: 903-914.

4. Nechushtan A, Smith CL, Lamensdorf I, Yoon SH, Youle RJ. Bax and Bak coalesce into novel mitochondria-associated clusters during apoptosis. J Cell Biol 2001; 153: 1265-1276

5. Chen L, Willis SN, Wei A, Smith BJ, Fletcher JI, Hinds MG et al. Differential targeting of prosurvival $\mathrm{Bcl}-2$ proteins by their $\mathrm{BH} 3-$ only ligands allows complementary apoptotic function. Mol Cell 2005; 17: 393-403.

6. Kuwana T, Bouchier-Hayes L, Chipuk JE, Bonzon C, Sullivan BA, Green DR et al. BH3 domains of BH3-only proteins differentially regulate Bax-mediated mitochondrial membrane permeabilization both directly and indirectly. Mol Cell 2005; 17: 525-535.

7. Willis SN, Fletcher JI, Kaufmann T, van Delft MF, Chen L, Czabotar PE et al. Apoptosis initiated when BH3 ligands engage multiple Bcl-2 homologs, not Bax or Bak. Science 2007; 315: 856-859.

8. Willis SN, Chen L, Dewson G, Wei A, Naik E, Fletcher Jl et al. Proapoptotic Bak is sequestered by $\mathrm{Mcl}-1$ and $\mathrm{Bcl}-\mathrm{xL}$, but not $\mathrm{Bcl}-2$, until displaced by $\mathrm{BH}$-only proteins. Genes \& Dev 2005; 19: 1294-1305.

9. Hsu YT, Wolter KG, Youle RJ. Cytosol-to-membrane redistribution of Bax and Bcl-X(L) during apoptosis. Proc Nat Acad Sci USA 1997; 94: 3668-3672.

10. Chen YB, Seo SY, Kirsch DG, Sheu TT, Cheng WC, Hardwick JM. Alternate functions of viral regulators of cell death. Cell Death Different 2006; 13: 1318-1324.

11. Cuconati A, White $E$. Viral homologs of BCL-2: role of apoptosis in the regulation of virus infection. Genes \& Dev 2002; 16: 2465-2478

12. Sundararajan $R$, Cuconati $A$, Nelson $D$, White $E$. Tumor necrosis factor-alpha induces BaxBak interaction and apoptosis, which is inhibited by adenovirus E1B $19 \mathrm{~K}$. J Biol Chem 2001; 276: 45120-45127.

13. Wasilenko ST, Banadyga $L$, Bond $D$, Barry $M$. The vaccinia virus $F 1 L$ protein interacts with the proapoptotic protein Bak and inhibits Bak activation. J Virol 2005; 79: 14031-14043.

14. Postigo A, Cross JR, Downward J, Way M. Interaction of F1L with the BH3 domain of Bak is responsible for inhibiting vaccinia-induced apoptosis. Cell Death Different 2006; 13: 1651-1662. 
15. Arnoult D, Bartle LM, Skaletskaya A, Poncet D, Zamzami N, Park PU et al. Cytomegalovirus cell death suppressor vMIA blocks Bax- but not Bak-mediated apoptosis by binding and sequestering Bax at mitochondria. Proc Nat Acad Sci USA 2004; 101: 7988-7993.

16. Poncet $D$, Larochette N, Pauleau AL, Boya $P$, Jalil AA, Cartron PF et al. An anti-apoptotic viral protein that recruits Bax to mitochondria. J Biol Chem 2004; 279: 22605-22614.

17. Su J, Wang G, Barrett JW, Irvine TS, Gao X, McFadden G. Myxoma virus M11L blocks apoptosis through inhibition of conformational activation of Bax at the mitochondria. J Virol 2006; 80: 1140-1151

18. Kvansakul M, van Delft MF, Lee EF, Gulbis JM, Fairlie WD, Huang DC et al. A structural viral mimic of prosurvival $\mathrm{Bcl}-2$ : a pivotal role for sequestering proapoptotic Bax and Bak. Mol Cell 2007; 25: 933-942.

19. Perez D, White E. TNF-alpha signals apoptosis through a bid-dependent conformationa change in Bax that is inhibited by E1B 19K. Mol Cell 2000; 6: 53-63.

20. Sundararajan R, White E. E1B $19 \mathrm{~K}$ blocks Bax oligomerization and tumor necrosis factor alpha-mediated apoptosis. J Virol 2001; 75: 7506-7516.

21. Cuconati A, Degenhardt K, Sundararajan R, Anschel A, White E. Bak and Bax function to limit adenovirus replication through apoptosis induction. J Virol 2002; 76: 4547-4558.

22. Hackenbrock CR. Ultrastructural bases for metabolically linked mechanical activity in mitochondria. I. Reversible ultrastructural changes with change in metabolic steady state in isolated liver mitochondria. J Cell Biol 1966; 30: 269-297.

23. Hackenbrock CR. Ultrastructural bases for metabolically linked mechanical activity in mitochondria. II. Electron transport-linked ultrastructural transformations in mitochondria. J Cell Biol 1968; 37: 345-369.

24. Rossignol R, Gilkerson R, Aggeler R, Yamagata K, Remington SJ, Capaldi RA. Energy substrate modulates mitochondrial structure and oxidative capacity in cancer cells. Cancer Res 2004; 64: 985-993.

25. Sheridan JW, Bishop CJ, Simmons RJ. Biophysical and morphological correlates of kinetic change and death in a starved human melanoma cell line. J Cell Sci 1981; 49: 119-137.

26. Gottlieb E, Armour SM, Thompson CB. Mitochondrial respiratory control is lost during growth factor deprivation. Proc Natl Acad Sci U S A 2002; 99: 12801-12806.

27. Scorrano L, Ashiya M, Buttle K, Weiler S, Oakes SA, Mannella CA et al. A distinct pathway remodels mitochondrial cristae and mobilizes cytochrome c during apoptosis. Develop Cell 2002; 2: 55-67.
28. Greenawalt JW, Rossi CS, Lehninger AL. Effect of active accumulation of calcium and phosphate ions on the structure of rat liver mitochondria. J Cell Biol 1964; 23: 21-38.

29. Pivovarova NB, Nguyen HV, Winters CA, Brantner CA, Smith CL, Andrews SB. Excitotoxic calcium overload in a subpopulation of mitochondria triggers delayed death in hippocampal neurons. J Neurosci 2004; 24: 5611-5622.

30. Gross A, Jockel J, Wei MC, Korsmeyer SJ. Enforced dimerization of BAX results in its translocation, mitochondrial dysfunction and apoptosis. EMBO J 1998; 17: 3878-3885.

31. Annis MG, Soucie EL, Dlugosz PJ, Cruz-Aguado JA, Penn LZ, Leber B et al. Bax forms multispanning monomers that oligomerize to permeabilize membranes during apoptosis. EMBO J 2005; 24: 2096-2103.

32. Huang Q, Petros AM, Virgin HW, Fesik SW, Olejniczak ET. Solution structure of the BHRF protein from Epstein-Barr virus, a homolog of human Bcl-2. J Mol Biol 2003; 332 $1123-1130$.

33. Uren RT, Dewson G, Chen L, Coyne SC, Huang DC, Adams JM et al. Mitochondria permeabilization relies on $\mathrm{BH} 3$ ligands engaging multiple prosurvival $\mathrm{Bcl}-2$ relatives, not Bak. J Cell Biol 2007; 177: 277-287.

34. Ott M, Robertson JD, Gogvadze V, Zhivotovsky B, Orrenius S. Cytochrome c release from mitochondria proceeds by a two-step process. Proc Natl Acad Sci USA 2002 99: 1259-1263

35. Germain M, Mathai JP, McBride HM, Shore GC. Endoplasmic reticulum BIK initiates DRP1-regulated remodelling of mitochondrial cristae during apoptosis. EMBO J 2005 24: $1546-1556$

36. Pinton $\mathrm{P}$, Rizzuto R. Bcl-2 and $\mathrm{Ca} 2+$ homeostasis in the endoplasmic reticulum. Cell Death Differ 2006; 13: 1409-1418.

37. Hardie DG, Hawley SA, Scott JW. AMP-activated protein kinase - development of the energy sensor concept. J Physiol 2006; 574: 7-15.

38. Robb-Gaspers LD, Burnett P, Rutter GA, Denton RM, Rizzuto R, Thomas AP. Integrating cytosolic calcium signals into mitochondrial metabolic responses. EMBO J 1998; 17: 4987-5000.

39. Pacher P, Hajnoczky G. Propagation of the apoptotic signal by mitochondrial waves. EMBO J 2001; 20: 4107-4121.

40. Szabadkai G, Simoni AM, Chami M, Wieckowski MR, Youle RJ, Rizzuto R. Drp-1dependent division of the mitochondrial network blocks intraorganellar $\mathrm{Ca} 2+$ waves and protects against Ca2+-mediated apoptosis. Mol Cell 2004; 16: 59-68.

Supplementary Information accompanies the paper on Cell Death and Differentiation website (http://www.nature.com/cdd) 